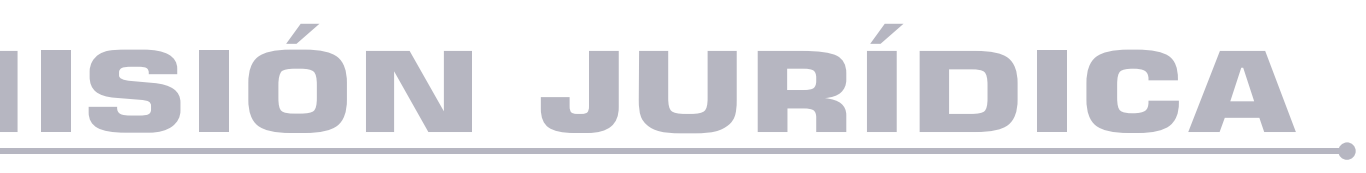

\title{
¿Son las bacrim un actor armado según el derecho internacional?
}

Are the bacrim an armed actor according to international law?

Autores: Víctor Hugo Mendoza Tovar, Víctor Hugo Ramírez Peña DOI: https://doi.org/10.25058/1794600X.992

\footnotetext{
SP MISIÓN JURÍDICA A 


\title{
¿SON LAS BACRIM UN ACTOR ARMADO SEGÚN EL DERECHO INTERNACIONAL?*
}

\author{
ARE THE BACRIM AN ARMED ACTOR \\ ACCORDING TO INTERNATIONAL LAW?
}

\author{
O BACRIM É UM ATOR ARMADO \\ DE ACORDO COM O DIREITO \\ INTERNACIONAL?
}

\section{RESUMEN}

El presente ensayo muestra de manera sucinta como las bandas de crimen organizado (BACRIM) o ahora como se les llama Grupos Armados Organizados (GAO) dejando como ejemplo el "Clan USUAGA", son actores participes del conflicto armado en Colombia y a diferencia de las guerrillas tradicionales (FARC y ELN), no se oponen al Estado, salvo cuando este último interfiere con sus actividades criminales, disputándose militarmente el poder local y regional a las guerrillas, mientras ejercían simultáneamente las conductas delictivas propias de su razón de ser criminal y la posibilidad de ser sujetos del Derecho Internacional Humanitario (DIH).

\section{* Artículo de reflexión.}

a. Profesional en Administración de sistemas e Informática de la Universidad Santo Tomas de Aquino - Colombia, Magister en Derechos Humanos y Derecho Internacional Humanitario de los Conflictos Armados de la Escuela Superior de Guerra - Colombia. MBA en Administración y Dirección de empresas de la Universidad Camilo José Cela - España, Candidato a Doctor en Gerencia y política educativa de la Universidad de Baja California - México. y Docente Investigador de la facultad de Administración de Empresas de la Universidad Minuto de Dios con sede en Madrid - Cundinamarca.

b. Licenciado en Filología e Idiomas, de la Universidad Libre de Colombia, Especialista en Gerencia de Proyectos, Universidad Minuto de Dios, Especialista en Gerencia Educativa. Universidad Minuto de Dios, Aspirante a Magister en Administración de Organizaciones. Universidad Nacional Abierta y a Distancia. Actualmente es Director del Centro Regional Madrid de la Rectoría Cundinamarca de UNIMINUTO 


\section{PALABRAS CLAVES}

Derecho Internacional Humanitario; Paramilitarismo; Bandas criminales; Bacrim; Comité Internacional Cruz Roja (CICR); Evolución bandolerismo en Colombia; Conflicto armado colombiano; guerra de guerrillas en Colombia.

\begin{abstract}
The present essay shows succinctly how the organized crime gangs (BACRIM) or now as they are called Organized Armed Groups (GAO), are actors participating in the armed conflict in Colombia and unlike the traditional guerrillas (FARC and ELN), they oppose the State, except when the latter interferes with their criminal activities, militarily contesting the local and regional power to the guerrillas, while simultaneously exercising the criminal conducts of their criminal raison d'être and the possibility of being subjects of International Humanitarian Law (DIH).
\end{abstract}

\section{KEYWORDS}

International

Paramilitarism: International Committee of the Red Cross (ICRC) Evolution banditry in Colombia; Colombian armed conflict; Partisan warfare in Colombia; Grupos Armados Ilegales (GAO).

\section{RESUMO}

0 presente ensaio mostra sucintamente como as gangues do crime organizado (BACRIM) ou agora como são chamados os Grupos Armados Organizados (GAO), deixando como exemplo o "Clã USUAGA", são atores participantes do conflito armado na Colômbia e ao contrário dos guerrilheiros tradicionais (FARC e ELN), não se opõem ao Estado, exceto quando este interfere em suas atividades criminosas, combatendo militarmente o poder local e regional para a guerrilha, ao mesmo tempo em que exerce as condutas criminosas de sua razão criminosa e a possibilidade de serem sujeitos do Direito Internacional Humanitário (DIH).

\section{PALAVRAS CHAVE}

Direito Internacional Humanitário; Paramilitarismo; Gangues criminosas; Bacrim; Comitê Internacional da Cruz Vermelha (CICV); Evolução do banditismo na Colômbia; Conflito armado colombiano; guerra de guerrilha na Colômbia.

\section{INTRODUCCIÓN}

Colombia es un país que durante gran parte de su historia ha afrontado una serie de conflictos armados, que han desembocado en guerras civiles o han mantenido diversas y constantes formas de manifestación de la violencia, ya manifiesta, ya latente, en especial en las áreas rurales, que desde los años cincuenta del siglo pasado provocó el desplazamiento de más de la octava parte de su población, situación que de nuevo se repitió a finales del siglo XX, y comienzos del XXI, entre otros factores, porque la instauración de la violencia por parte de los actores armados ha tenido la intencionalidad de posibilitar el despojo de las tierras al campesinado, encubriendo dicha expoliación con aparentes razones políticas.

El presente ensayo tiene como objetivo, mostrar que en Colombia la lucha armada tiene un actor "invisible" para la comunidad internacional, es el caso de las Bandas Criminales (BACRIM) o Grupos Armados Organizados (GAO), se habla de conflicto interno armado colombiano entre Guerrillas y Estado, pero evidentemente existen alternamente a estos otros grupos, otros también organizados cuya presencia ya no es en la parte rural si no en las ciudades, dificultando a las fuerzas militares su contención y posterior reducción.

Los GAO o BACRIM no se pueden bombardear como en casos vistos con la guerrilla de las FARC (campamento del guerrillero Raúl Reyes) pues el daño colateral tendría unos daños humanitarios de proporciones devastadoras, entonces es la policía Nacional la encargada de contener estos fenómenos sociales, enfrentándose a estos grupos con una estructura organizada, con mando responsable, y ejerciendo control de una parte del territorio.

\section{Caracterización de la banda criminal o grupo armado organizado como actor del conflicto armado interno}

Surge la cuestión de si las bandas de crimen organizado son actores del conflicto armado en Colombia. Estos grupos, a diferencia de los tradicionales grupos armados, no se oponen al Estado, salvo cuando este último interfiere con sus actividades criminales; a su vez, no tienen aspiraciones políticas (Vité, 2009). 
Aunque algunos argumentan que vista la falta de aspiraciones políticas reales no es posible considerar a una BACRIM o GAO y como un ejemplo al "Clan Úsuga" como parte del Conflicto Armado No Internacional (en adelante CANI), tanto el CICR como los Tribunales internacionales, interpretando las normas aplicables del Derecho Internacional Humanitario (en adelante DIH), han manifestado que la determinación de la existencia de un conflicto armado, y del carácter de actor parte en el mismo, se basa solamente en dos criterios: la intensidad del conflicto y el nivel de organización de las partes. Por consiguiente, el propósito por el cual el grupo armado se involucró en acciones de violencia, o si este logró algún objetivo por medio de dichas acciones es irrelevante (Caso Limaj, 2007).

A nivel interno, la Corte Constitucional se ha manifestado en este sentido. En la Sentencia C-291 de 2007 el Corte usó la jurisprudencia del caso Limaj del TPIY y declaró que:

[...] para efectos de la aplicación del Derecho Internacional Humanitario, la existencia de un conflicto armado se determina jurídicamente con base en factores objetivos, independientemente de la denominación o calificación que le den los Estados, Gobiernos o grupos armados en él implicados. [...] para efectos de establecer en casos concretos si un determinado conflicto ha trascendido el umbral de gravedad necesario para ser clasificado como un conflicto armado interno, la jurisprudencia internacional ha recurrido principalmente a dos criterios: (i) la intensidad del conflicto, y (ii) el nivel de organización de las partes, [...] al apreciar la intensidad de un determinado conflicto, las Cortes internacionales han aplicado, por ejemplo, factores tales como la seriedad de los ataques y si ha habido un incremento en las confrontaciones armadas, la extensión de las hostilidades a lo largo de un territorio y de un período de tiempo, el aumento en las fuerzas armadas estatales y en su movilización, así como la movilidad y distribución de armas de las distintas partes enfrentadas. En cuanto a la organización de los grupos enfrentados, las cortes internacionales la han apreciado de conformidad con criterios tales como la existencia de cuarteles, zonas designadas de operación, y la capacidad de procurar, transportar y distribuir armas" (Corte Constitucional, 2007)
A su vez, ese mismo tribunal, por medio de las Sentencias C-781 de 2012 y C-577 de 2014, ha reiterado que se debe entender al CANI de forma amplia incluyendo "toda la complejidad y evolución fáctica e histórica del conflicto [...], en el que se hace patente la dificultad para separar los fenómenos de violencia generalizada y delincuencia común, del accionar de los actores armados en el contexto del conflicto armado" (Corte Constitucional, 2014).

Como se señaló en líneas anteriores, para que un colectivo armado pueda ser considerado parte de un CANI, el mismo debe i) Tener un mando organizado y responsable; ii) Ejercer control sobre un parte de un territorio, y iii) Ejecutar operaciones militares sostenidas. A su vez, sus acciones deben superar un umbral mínimo de violencia.

\section{Grupo Armado Organizado}

El artículo 1 del Protocolo II no reconoce expresamente un concepto de actor armado, sino que de forma descriptiva señala que un CANI se da cuando existan:

[...] fuerzas armadas disidentes o grupos armados organizados que, bajo la dirección de un mando responsable, ejerzan sobre una parte de dicho territorio un control tal que les permita realizar operaciones militares sostenidas y concertadas y aplicar el presente Protocolo (Artículo 1, Protocolo II).

En virtud de la interpretación de la Corte Penal Internacional (en adelante CPI) del DIH, un actor armado, en primer lugar, debe tener nivel de organización; en segundo lugar, capacidad de planificar sus estrategias militares; en tercer lugar, capacidad de daño, y, en cuarto lugar, capacidad de mantener operaciones sostenidas (Caso Abu Garda, 2010). A continuación, se analizan estos elementos para el caso concreto de las "BACRIM o GAO".

\section{Mando Responsable}

Como se señaló en la parte inicial, las BACRIM tienen un mando central representado en la figura del líder máximo y cabeza visible de la organización, en el caso del clan USUGA (inicialmente conformado por Daniel Rendón, luego por Juan de Dios Úsuga y actualmente por Darío Antonio Úsuga), y la representación de mandos de cada uno de los Bloques que 
integran el "Estado Mayor General". A su vez, su funcionamiento se basa en una estructura en red por niveles, en la que existe i.) Un nodo central organizado en torno al "Estado Mayor General” como primer nivel; ii.) Una organización descentralizada a través de sus bloques como el segundo nivel, y iii.) El relacionamiento con estructuras externas (cooptadas, pero con autonomía), que se convierte en el tercer nivel de actuación de la organización.

A modo de ejemplo de hechos que cumplen con este requisito $\mathrm{y}$, por consiguiente, manifiestan una configuración del mando responsable, se puede mencionar que:

i. Existe una serie de panfletos y un documento informativo que expresan sus posiciones sobre distintos temas, operaciones y fines;

ii. Tiene estatutos y reglamentos, públicos desde el 2014;

iii. En sus comunicados públicos mantiene una voz única;

iv. Según la operación Agamenón se descubrió que tienen campamentos y centros de operación en medio de la selva del Urabá antioqueño y chocoano, $y$

v. Tiene uniformes y distintivos.

\section{Control sobre una parte del territorio}

Desde sus inicios, la concentración del dominio territorial del "Clan Úsuga" se ha centrado en ciertas áreas que fueron heredadas de los Bloques Elmer Cárdenas, Bloque Bananero y Bloque Mineros de las AUC, como son el Sur Bolívar, Nordeste Antioqueño y el Urabá, y en la actualidad su presencia se extiende por, al menos, 146 municipios en 12 departamentos. En las zonas de concentración el grupo ha logrado eliminar a sus competidores armados y ejerce un control casi absoluto sobre la población.

Tanto en las zonas de hegemonía, como en las zonas de disputa, el grupo ha utilizado la violencia como mecanismo de control territorial, haciendo uso de mecanismos como los paros armados, amenazas y la eliminación selectiva de líderes sociales, defensores de derechos humanos y reclamantes de tierras, los cuales cuestionan su autoridad local, y lideran procesos en contra de la concentración de la tenencia de la tierra, la cooptación política local, entre otros.
Un ejemplo de este control social se puede evidenciar en lo sucedido en las veredas del corregimiento de Guachaca en Magdalena, donde la agrupación convocó a reuniones ordenando la expulsión de las personas de apellido Giraldo y sus colaboradores. Como consecuencia de la confrontación el corregimiento de Guachaca se ha convertido en uno de los principales lugares de expulsión de población. De acuerdo con las declaraciones de personas en situación de desplazamiento recibidas por la Defensoría Regional Magdalena en el periodo 14 de diciembre de 2012 a 24 de marzo de 2013, se establece que cerca de 160 personas habían abandonado la vereda Marquetalia, que tiene una población aproximada de 1200 habitantes distribuidos en 300 viviendas (Defensoría del Pueblo, 2013a; Fiscalía General de la Nación, 2013a).

Otros ejemplos de este control se evidencian en hechos como: i) El paro armado del año 2008, en el cual cesa toda actividad en la región del Urabá y hacen pública su autodenominación como Autodefensas Gaitanistas de Colombia; ii) El segundo paro armado de 2012, donde interrumpieron la actividad comercial, el trasporte y la institucionalidad pública en alrededor de 20 municipios de la región del Urabá y zonas aledañas, y iii) El control continuo en el Urabá chocoano, en las cuencas de los ríos Jiguamiando y Curvaradó, así como en el Río Cacarica, donde mantienen el dominio de los cultivos de palma de aceite en los territorios colectivos (Comisión Colombiana de Juristas, 2011). iv) El alto control territorial de Segovia y Zaragoza mediante la extorsión de mineros, y la explotación ilegal (Fundación Ideas para la Paz, 2015a), y v) La presencia y constante disputa con los Rastrojos en el Sur de Bolívar por el corredor estratégico del magdalena medio (Centro Nacional de Memoria Histórica, 2014).

Sin embargo, el control territorial por parte del "Clan Úsuga" ha sido un proceso de reconfiguración progresiva como actor armado luego de las desmovilizaciones del 2006, razón por la cual el debilitamiento sufrido entre los años 2006 y 2007 hizo que perdiera parte del dominio en las zonas que pertenecieron, tradicionalmente, a las estructuras paramilitares que precedieron a este grupo. Más allá de esto, desde 2008 la organización ha recuperado estos territorios y ha ganado muchos más gracias a la nueva lógica organizacional. 
Así mismo, el crecimiento de su presencia entre los años 2008 y 2012, período en el cual pasó de tener presencia en 20 municipios a ser reportados en, al menos, 146 de 12 departamentos, muestra como este actor ejerce un dominio territorial amplio en las zonas periféricas del país.

\section{Operaciones militares sostenidas y concertadas}

Aunque durante los años 2006 y 2007 la incidencia del grupo en la violencia no presenció una capacidad de operaciones militares sostenidas, desde 2008, y en particular desde su reestructuración en 2009, sí lo logró pudiendo consolidarse y extender su presencia territorial a nuevas zonas, aumentando así los índices de violencia en las mismas como consecuencia de los enfrentamientos que la banda entabló con grupos presentes allí. A modo de ejemplo, como ya se manifestó, en 2008 el "Clan Úsuga" se expandió hacia el Nudo de Paramillo y Bajo Cauca Antioqueño motivo por el cual entró en conflicto con "Los Paisas" y aumentó tanto la tasa de homicidios como la de desplazamientos en dichos municipios (Defensoría del Pueblo, 2009; Fundación Ideas para la Paz, 2014).

Otro ejemplo del aumento de los índices directamente relacionado con el crecimiento de este grupo es el departamento de Nariño, donde en 2014 se reportó la Alerta Temprana por presencia de dicho grupo en el Municipio de Barbacoas, lugar que se disputa con las guerrillas.

En relación con los factores que indican que el grupo podía realizar operaciones de una manera organizada, como se mostró, el control del "Clan Úsuga" está basado en la capacidad y disciplina militar, cuestiones que se reflejaban en los dos paros armados realizados tanto en 2008 como en 2012 y que incluyeron a varios municipios en forma coordinada. Tanto la capacidad como el dominio territorial se evidencian en la tasa de homicidios en Medellín durante los IX Juegos Suramericanos que se llevaron a cabo entre el 17 y el 30 de marzo de 2010, con solo 2 homicidios, cuando ese mismo año la tasa de homicidios fue de 5,9 casos diarios (Secretaría de Gobierno de Medellín, 2011).

Así mismo, se han tomado en consideración los factores relevantes para determinar si un grupo armado posee el nivel de disciplina y la capacidad de aplicar sus obligaciones básicas con arreglo al artículo 3 común. Estos requisitos han sido expedidos a través de los estatutos y el reglamento disciplinario de la organización que hicieron público en el año 2014.

De igual forma, se debe precisar que, según la Fiscalía General de la Nación, en 2015, 2970 integrantes del "Clan Úsuga" hacían presencia territorial en 146 municipios de 12 departamentos. Este aumento en la presencia territorial y en el número de integrantes muestra la capacidad de reclutamiento de el "Clan Úsuga" (Gaceta del Congreso No. 404 de 2015). A modo de ejemplo, sólo en la Comuna 8 de Medellín el grupo ha reclutado a 120 adolescentes de entre 13 y 18 años en 2012 (Defensoría del Pueblo, 2012b).

A su vez, el tipo de hostilidades o violencia ejercida por la estructura armada también cumple con los requisitos internacionales. En este sentido, el "Clan Úsuga" no mantiene enfrentamientos constantes con la fuerza pública y otros actores armados, pero sí registra hechos de violencia que tienen como objetivo consolidar su control territorial en las distintas regiones. Así, como ya se mencionó, el grupo se enfrentó con "Los Paisas" y luego con "Los Rastrojos" por el control del Nudo de Paramillo y Bajo Cauca Antioqueño. A su vez, se enfrentó al ELN por el control de la zona del Bajo Atrato chocoano, territorio en el que incursionaron aproximadamente 300 de sus integrantes el 3 de septiembre de 2015, y otros 500 integrantes el 14 de octubre hasta la cuenca media del río Truandó. Existen asimismo reportes de enfrentamientos armados contra miembros del ELN del 9 de septiembre, 7 de octubre, 14 de octubre (Defensoría del Pueblo, 2014a).

\section{Intensidad}

Según el DIH es necesario que las operaciones militares ejercidas por un grupo tengan un nivel de intensidad tal para que se considere que se configura un CANI; esto a fin de excluir el bandidaje, los disturbios civiles, y las insurrecciones desorganizadas y fugaces. Como lo manifestó la $\mathrm{CIDH}$, el núcleo de la cuestión es determinar el "extremo inferior" de la escala de violencia interna para poder determinar si se aplica el DIH (Caso La Tablada, 1997).

Luego de una extensa jurisprudencia, en el caso Dordevic de 2011 el TPIY sistematizó 
y detalló los lineamientos para analizar si un hecho supera el umbral de violencia, retomando así los presupuestos del caso Haradinaj del mismo Tribunal. Estos son: a) La gravedad de los ataques y el aumento de los choques armados; b) La propagación de choques en el territorio y en un lapso de tiempo; c) El aumento en la cantidad de fuerzas del gobierno, en la movilización, y en la distribución de armas entre ambas partes en conflicto; d) Si el conflicto ha suscitado la atención del Consejo de Seguridad de las Naciones Unidas, y si se ha adoptado alguna resolución sobre el asunto; e) La cantidad de civiles que se han visto obligados a huir de las zonas de combate; f) Los tipos de armas utilizadas, en particular el uso de armamento pesado y otro equipamiento militar, como tanques y otros vehículos pesados; g) Los bloqueos y los sitios a ciudades, y el intenso bombardeo de artillería a estas ciudades; h) Los niveles de destrucción y la cantidad de muertos causados por los bombardeos o los combates; i) El número de tropas y unidades desplegadas; j) La existencia y el cambio en las líneas de vanguardia entre las partes; k) La ocupación de territorio, y de ciudades y aldeas; l) El despliegue de fuerzas del gobierno en una región en crisis; m) El cierre de rutas; n) Las órdenes o acuerdos de alto al fuego y el intento de los representantes de organizaciones internacionales de mediar y de velar por la observancia de los acuerdos de alto al fuego, y o) El elevado número de bajas así como la extensión de la destrucción material (Caso Dordevic, 2011).

Para el caso del "Clan Úsuga", se evidencia que más allá de los dos paros armados de 2008 y 2012 mencionados, el grupo ha sido responsable de restricciones a la movilidad, bloqueos alimentarios y confinamientos de la población civil (Defensoría del Pueblo, 2014 b; Defensoría del Pueblo, 2013b; Defensoría del Pueblo, 2012c. A modo de ejemplo, en el primer trimestre de 2014 produjo el confinamiento de 1.900 habitantes de las comunidades indígenas y afrodescendientes en el Medio y Alto Baudó (Defensoría del Pueblo, 2014a).

Por otro lado, este grupo fue identificado como responsable de desplazamientos masivos, reclutamiento de menores, desapariciones, violencia sexual y amenazas, en especial a defensores de Derechos Humanos y políticos (Defensoría del Pueblo, 2012b; Defensoría del
Pueblo, 2014a; Fiscalía General de la Nación , 2014; CIDH, 2013; Misión de Apoyo al Proceso de Paz, 2011; Caso Carlos Andrés Abad David, 2013). A modo de ejemplo, en 2011 y 2012 fueron sentenciados por concierto para delinquir con fines, entre otros, de desplazamiento forzado 51 miembros del "Clan Úsuga" que operaban en Caucasia, Tarazá y Cáceres (Antioquia). 10 integrantes del Ejército y la propia Policía también fueron sentenciados por vender información a los ilegales (Fiscalía General de la Nación, 2013e). En 2013 fueron condenados cinco integrantes de la banda por el desplazamiento forzado de unas 50 personas en el suroccidente de Medellín entre octubre de 2010 y mayo de 2011 (Fiscalía General de la Nación , 2013f)

A su vez, varios organismos han denunciado constantes casos de reclutamiento de menores, violencia sexual y amenazas y homicidios de Defensores Humanos cometidos por este grupo (CIDH, 2013; Mesa de trabajo mujer y conflicto armado, 2012; Fundación Ideas para la Paz, 2015a). En el caso específico de reclutamiento forzado, como ya se mencionó, solo en la Comuna 8 de Medellín el grupo ha reclutado a 120 adolescentes de entre 13 y 18 años (Defensoría del Pueblo, 2012c).

Por otro lado, se le han incautado fusiles AK47, 7.62 MM, fusiles de asalto M16, COLT 5.56 MM, lanza granadas $\mathrm{M} 79$, morteros de $60 \mathrm{MM}$, granadas de fragmentación, pistolas $9 \mathrm{MM}$, ametralladoras M60 STANDARD, armas automáticas UZI, mini UZI, INGRAM y pistolas Fivesentent. (Policía Nacional, 2015; Caso Edwin Bermúdez Granados, 2013; Gaceta del Congreso No. 404 de 2015; Grupo Interinstitucional C13 Crimen Organizado, 2013) A modo de ejemplo, en agosto de 2012, en el municipio de Los Patios (Norte de Santander), fue capturado Nelson Javier Prieto y se incautaron nueve fusiles, dos subametralladoras, dos pistolas con silenciador, tres escopetas Mossberg, dos armas de fuego calibre 38, cinco teléfonos satelitales, 4000 cartuchos de diferentes calibres, dos radios de comunicaciones y uniformes militares (Fiscalía General de la Nación, 2013d). En octubre de 2012 se descubrió un depósito de armamento del "Clan Úsuga" en cercanías del aeropuerto de Amalfi, noreste de Antioquia, donde las autoridades incautaron seis fusiles, 84 proveedores, 29 granadas, y uniformes militares, entre otros elementos (Fiscalía General de la Nación , 2012). 
De igual modo, según datos de los resultados y el material bélico incautado en el operativo Agamenón, coordinado entre las Fuerzas Militares y la Policía Nacional y que incluyó el bombardeo a los campamentos del Clan Úsuga en la región de Urabá chocoano en noviembre de 2015, a comienzos de 2015 se tenía un saldo de:

12 integrantes neutralizados; 1 herido, 5 campamentos destruidos, 14 fusiles incautados discriminados así: 8 fusiles AK47, 1 fusil Galil, 2 fusiles G3, 2 Falcon, 1 R15, 1 ametralladora, 1 mortero, 2 granadas de 60 mm, 2 granadas IM26, 3 minas artesanales y 17 proveedores 1269 cartuchos de 7.62 (General Palomino citado en La F.M. (11/3/2015)).

Este tipo de armamento se ha visto en operaciones no solo contra otros grupos o en zonas aisladas, sino en zonas urbanas y contra civiles. Es así que, en Santa Marta el 24 de octubre de 2012 este grupo activó una granada en el supermercado Rapimercar con el saldo de una menor de siete años muerta (Fiscalía General de Colombia, 2013a, a su vez, en Cúcuta, el 20 de abril de ese mismo año el "Clan Úsuga" activo otra granada en un comercio (Fiscalía General de Colombia, 2015).

Respecto del criterio del número de tropas y unidades desplegadas por parte del gobierno, cabe anotar que el Estado Colombiano ha puesto en marcha varias operaciones en contra de esta Bacrim entre las que se encuentran las mencionadas Operaciones Troya I, Troya II y Agamenón, esta última compuesta por 1.200 efectivos de la Policía y 1.000 del Ejercito Nacional, y una flotilla de helicópteros artillados; lo cual demuestra el grado de intensidad del conflicto entre el Estado y estos colectivos armados.

\section{Fin de la desmovilización de las AUC y surgimiento de las Bacrim: período 2007 - 2015}

Luego de la desmovilización de las AUC, en el país persistió el conflicto armado debido a la continuidad de las guerrillas, y la creación o resurgimiento de agrupaciones que se consolidaron en forma similar a la última etapa de la confederación AUC: heterogéneos y con fuertes relaciones con el narcotráfico y otro tipo de economías ilegales.
Los fenómenos delictivos constituidos por secuelas del paramilitarismo fueron prontamente bautizados por la Policía Nacional como bandas criminales, para diferenciarlos de los grupos armados que, habiéndose desmovilizado, estaban surtiendo un proceso de reincorporación a la vida civil (Centro Nacional de Memoria Histórica, 2014c). Sin embargo, las conexiones entre las nacientes estructuras y los antiguos grupos paramilitares se dieron tanto a nivel geográfico, como en las prácticas de control territorial y en las fuentes de financiación utilizadas (Fundación Ideas para la Paz, 2013).

Es así que a partir del 2005 comienza a ser evidente la persistencia de grupos armados con fuertes relaciones con el narcotráfico que ocupaban zonas de los antiguos grupos de las AUC ${ }^{1}$, y ya en 2007 se reportó que los grupos guerrilleros no habían ocupado la zona de influencia de las AUC, sino que habían nuevos grupos armados allí que no solo se localizan en las mismas zonas, sino que también se encuentran bajo el control de narcotraficantes que son parientes o segundos mandos de los jefes desmovilizados (Misión de Apoyo al Proceso de Paz, 2007).

Inicialmente, estos grupos tenían presencia en La Guajira, norte y sur del Cesar, Córdoba,

1. A modo de ejemplo se cita el Sexto Informe Trimestral de Secretario General al Consejo Permanente sobre la Misión de Apoyo al Proceso de Paz en Colombia, del 16 de febrero de 2006, el cual manifiesta que se han identificado grupos de desmovilizados que se han reagrupado en:

1. El municipio de Palmito, departamento de Sucre (zona de influencia del ex bloque Héroes Montes de María) en donde un grupo de alrededor de ocho desmovilizados ejerce control social sobre la población y en especial en el casco urbano; 2. En la sub región de la Mojana, específicamente en los Municipios de Majagual, Guaranda y Sucre (área de influencia del ex frente la Mojana) un grupo de siete individuos incluido un ex comandante delfrente estaría ejerciendo extorsión sobre algunos comerciantes. Según información y denuncias, el grupo también está ejerciendo "limpieza social"; 3. En el municipio de Montelíbano, Departamento de Córdoba (área de influencia del ex Bloque Sinú y San Jorge) hay un grupo de alrededor de 25 individuos entre los que se encuentran desmovilizados, que controlan al comercio de drogas ilícitas y ejercen intimidación hacia la población civil 4. En el corregimiento La Cristalina en Puerto Gaitán, Meta (área de influencia de las ex Autodefensas Campesinas de Meta y Vichada), un grupo de cinco desmovilizados extorsionan el transporte de alimentos; 5. En barrios de Buenaventura, Valle del Cauca (área de influencia del ex Bloque Calima), después de la captura de un desmovilizado, hubo una violenta dinámica que arrojó 14 desmovilizados muertos; 6. En zona rural de Palmira y en Florida, Valle (también del ex Bloque Calima), un grupo de desmovilizados se dedica a la extorsión; 7. En Tumaco, Nariño (área de influencia del ex Bloque Libertadores del Sur), se ha recibido información sobre desmovilizados que ejercen cierto control sobre la comercialización de narcóticos (Misión de Apoyo al Proceso de Paz (1), 2006, págs. 7-8). 
Magdalena, sur de Bolívar, Norte de Santander, Urabá y el occidente de Antioquia, Vichada, Meta, Casanare, Arauca, Nariño, Tolima, Putumayo, Caquetá, Chocó y Caldas, y aunque se seguían presentando hechos de violencia, como homicidios, los mismos se reportaban en niveles moderados y principalmente en el marco de disputas al interior del narcotráfico (Fundación Ideas para la Paz, 2013).

La Fundación Seguridad y Democracia en el 2007 declaró que "la tipología de los nuevos grupos armados depende de la importancia y condición estratégica de los territorios donde surgieron estos mismos" (Fundación Seguridad y Democracia, 2007: 3). Igualmente, argumentó que existían tres factores que explicaban la presencia de estos grupos en dichas zonas,

a) El desarrollo de economías ilícitas ya sea el narcotráfico o el tráfico de armas, combustible y precursores químicos para el procesamiento de alcaloides, etc.; b) Las circunstancias geoestratégicas de las zonas como la existencia de rutas y puertos para la comercialización de la droga y la presencia de corredores que faciliten la movilidad y ocultamiento de los grupos armados; y c) El nivel de disputa territorial con otras organizaciones armadas como las guerrillas, mafias del narcotráfico y delincuencia organizada (Fundación Seguridad y Democracia, 2007: 3)

\section{8. ¿Son las Bacrim una Continuación del Paramilitarismo?}

Múltiples pronunciamientos, entre los que se destacan los de la Alta Comisionada de Derechos Humanos (en adelante ACNUDH) coinciden en identificar a estos grupos armados como estructuras que hacen parte del conflicto y que cometen violaciones masivas a los derechos humanos. En este sentido, la ACNUDH expresó que,

(...) entre los actos de violencia cometidos por estos grupos en 2009, se registraron masacres, asesinatos selectivos, amenazas, desplazamientos forzados $y$ violencia sexual. Entre las víctimas de estos grupos hay líderes y lideresas sociales, indígenas, afrocolombianos y funcionarios locales, en muchos casos vinculados con procesos de restitución de tierras o manejo de recursos públicos. Los ataques han estado dirigidos contra quienes se oponen a las exigencias de estos grupos, poseen propiedades de su interés, son percibidos como colaboradores o miembros de otros grupos, o están en una zona de disputa con grupos rivales. Entre las víctimas también hay numerosos desmovilizados por ajustes de cuentas o por negarse a integrarse a estos grupos.

Algunos de estos grupos operan de un modo parecido a las antiguas organizaciones paramilitares, y participan en actividades criminales tales como narcotráfico, extorsión, despojo de tierras, prostitución y trata de personas, así como en actividades lícitas, aunque a veces irregulares, como loterías y seguridad privada. En las filas de estos grupos hay personas desmovilizadas y no desmovilizadas de las antiguas organizaciones paramilitares, reclutadas voluntaria o forzadamente. Varios de los actuales cabecillas fueron anteriormente mandos medios de esas organizaciones o militares (Alta Comisionada de las Naciones Unidas para los Derechos Humanos, 2010: 59 - 61).

Por otro lado, organizaciones de la sociedad civil han expresado que estos grupos rearmados, emergentes y disidentes, son estructuras neoparamilitares, básicamente al tenor de seis argumentos (Comisión Colombiana de Juristas, 2013).

a) Continuidad de los integrantes de las AUC. En este sentido, "casi todos los líderes de los grupos sucesores [de los paramilitares] son jefes de las AUC de rango medio que nunca se desmovilizaron o que continuaron participando en actividades delictivas pese a que aparentaron haberse sumado a la desmovilización" (Human Rights Watch, 2010). En tal sentido, las estructuras de los grupos paramilitares no solo se mantienen, sino que, más que una desmovilización y/o reconfiguración, lo que se ha producido es una transmisión de mando.

b) Cumplen con los requisitos del Protocolo II adicional a los Convenios de Ginebra. Este análisis se suma al enunciado anteriormente, según el cual la persistencia del paramilitarismo se evidencia en que los mandos medios de las estructuras existentes antes de la supuesta desmovilización lideran hoy en día los nuevos grupos (Comisión Colombiana de Juristas, 2013: 4). 
c) Los vínculos entre estas bandas y las fuerzas de seguridad del Estado continúan. A este respecto, la situación es de tal magnitud que, según el Ministerio de Defensa, han sido retirados 350 militares por sospechas de vínculos con las bandas criminales, y desde 2008 en la Policía se han realizado 319 investigaciones contra 888 de sus miembros, producto de las cuales 287 funcionarios fueron retirados y denunciados penalmente por sus vínculos con estos grupos (Alta Comisionada de las Naciones Unidas para los Derechos Humanos, 2011).

d) "la Comisión Colombiana de Juristas ha registrado que entre el $1^{\circ}$ de diciembre de 2002 y el 30 de junio de 2009 por lo menos 4.820 [civiles] han perdido la vida [...] por [acción] de grupos neoparamilitares" (Comisión Colombiana de Juristas, 2013: 5).

e) Se mantiene el perfil de las víctimas. "Estos grupos atacan a líderes sociales, defensores y defensoras de derechos humanos, pueblos indígenas y comunidades afrocolombianas, entre otros sectores, tal como lo constató la Alta Comisionada de las Naciones Unidas para los Derechos Humanos en su informe de 2010" (Comisión Colombiana de Juristas, 2013: 5). Según algunos estudios, "los neoparamilitares existen para mantener lo que los paramilitares lograron. La presión violenta en contra de los líderes de las víctimas que buscan la restitución de sus tierras y de otros movimientos sociales solo puede explicarse así" Restrepo, J., González, J., \& Tobón, A. (2011).

Esta política de ataques es propia de las formas de operar de grupos paramilitares, que se han ocupado durante años de perseguir a la población civil, y en particular a quienes se organizan para exigir sus derechos y a las personas socialmente marginadas (Comisión Colombiana de Juristas, 2013).

f) Intensidad del ejercicio de la violencia. Al respecto, la Alta Comisionada de Naciones Unidas para los Derechos Humanos, en su informe del 2010 señaló que, como se puede deducir de los casos presentados, "la presencia de grupos armados ilegales surgidos de la desmovilización de organizaciones paramilitares es motivo de preocupación por su expansión y por la intensidad de los actos de violencia que han cometido contra la población" (Comisión Colombiana de Juristas, 2013: 5).
El reconocimiento de las Bacrim, o algunas de ellas, como tercer actor del conflicto armado ha sido una disyuntiva que afronta el Estado colombiano pero que, a la luz de lo discutido anteriormente, no es un problema novedoso sino jamás superado. Varios organismos internacionales, tanto del Sistema Interamericano de protección de DDHH como del Sistema Universal, han visto, en la negativa del gobierno para pronunciarse, una extensión de las violaciones derechos humanos a las víctimas del conflicto que no encuentran una respuesta en la institucionalidad y que, por el contrario, siguen siendo revictimizadas por estos "nuevos actores" en los territorios.

En efecto, y luego de finalizado el proceso de desmovilización colectiva, la CIDH tomó nota de que fue poca la información dada a conocer al público sobre aquellos desmovilizados que, sin participar del proceso de reinserción, se rearmaron o formaron nuevas organizaciones persistiendo en la violencia. Sobre ese panorama tuvo por probada la existencia de manifestaciones de violencia posteriores a las desmovilizaciones que obedecían a dinámicas tales como el reagrupamiento de desmovilizados en bandas delincuenciales con control sobre comunidades específicas y economías ilícitas; reductos que no se desmovilizaron, y la aparición de nuevos actores armados y/o fortalecimiento de algunos ya existentes en zonas abandonadas por los grupos desmovilizados (Comisión Interamericana de Derechos Humanos, 2009).

La CIDH también indicó que, pese a la desmovilización de las AUC, persistía la violencia derivada del conflicto armado, y se mantenían las denuncias sobre la comisión de crímenes, violaciones a los derechos humanos e infracciones al DIH contra la población civil por parte de grupos armados al margen de la ley y miembros de la fuerza pública, que se traducían en violaciones del derecho a la vida, la integridad personal y la libertad y redundaban en la continuidad del desplazamiento forzado (Comisión Interamericana de Derechos Humanos, 2009).

A su vez, consideró que, a pesar de los esfuerzos destinados a desarticular las estructuras de las AUC, los grupos armados ilegales continuaban involucrados en la comisión de actos de hostigamiento y violencia contra poblaciones vulnerables, líderes sociales y defensores de derechos 
humanos (Comisión Interamericana de Derechos Humanos, 2009). La CIDH observó también que "en algunas ciudades capitales y municipios, se había recrudecido la práctica de delitos de alto impacto como los homicidios, generalmente ejecutados mediante la modalidad de sicariato" (Comisión Interamericana de Derechos Humanos, 2013b: 50). También ha denunciado la interferencia de los grupos armados ilegales en la gestión de algunas administraciones locales y departamentales, así como la cooptación de candidatos, movimientos y campañas políticas (Comisión Interamericana de Derechos Humanos , 2013b).

De la misma manera, la MAPP-OEA reportó que en algunas zonas del país habían reaparecido las masacres y las amenazas, ligadas a la denominada "limpieza social" contra algunas poblaciones vulnerables que eran generalmente atribuidas a las denominadas "bandas emergentes" (Misión de Apoyo al Proceso de Paz, 2007).

La CNRR, a propósito de lo anterior, sostiene que:

[...] se produjo la desmovilización de las AUC pero sobrevino una diáspora de grupos armados ilegales que van desde expresiones disidentes y rearmadas con varios rasgos similares al paramilitarismo hasta numerosas bandas delincuenciales. Estos grupos armados emergentes asumen una nueva e intensa disputa por el control del narcotráfico, otras formas de ilegalidad, control de territorios, aliados y apoyos, de manera que se desatan cruentos enfrentamientos en varias regiones y en algunas ciudades. Se presenta una mayor persecución de las fuerzas estatales contra este tipo de nuevos grupos armados ilegales y bandas delincuenciales, a la vez que, en aprovechamiento del narcotráfico, existen alianzas y acuerdos entre frentes guerrilleros y grupos rearmados con presencia de ex paramilitares.

Los grupos armados ilegales que han emergido buscan reproducir escenarios de control coercitivo contra los pobladores, en especial contra comunidades rurales y urbanas donde concentran su acción y contra determinados sectores sociales y poblacionales. Realizan presiones y ataques armados que ocasionan desplazamientos forzados y despojo de tierras, amenazas, homicidios y desapariciones forzadas. Si bien el volumen de tales actuaciones y el impacto territorial no son generalizados sino de particular impacto en localidades y en varias regiones y distan de la magnitud de la cruenta ocupación territorial paramilitar anterior, no son desestimables y en algunos contextos particulares son de iguales efectos (Comisión Nacional de Reparación y Reconciliación, 2010: 116).

Resalta la CNRR que estas agrupaciones ejercen control social y político con diferentes niveles de intensidad y en ámbitos más restringidos, se constituyen en poderes locales de facto, imponen reglas, atacan violentamente cualquier oposición o resistencia y aplican la llamada 'limpieza social'. Por tales circunstancias algunos informes afirman que su actuación debe interpretarse como la continuación del paramilitarismo (Comisión Nacional de Reparación y Reconciliación, 2010: 208).

Es por ello que desde el año 2010, este organismo ha indicado que las organizaciones criminales surgidas después de la desmovilización de las AUC se crearon como una nueva forma de paramilitarismo, considerada como la tercera generación de los grupos paramilitares en Colombia, y cuyo propósito inicial es la conservación del dominio territorial de los frentes de esta confederación. Estas estructuras han buscado retomar el control, no sólo territorial, sino económico, logístico y social en las zonas de influencia en donde venían delinquiendo los grupos paramilitares, además de intentar su expansión a otras regiones, en las que tuvieron injerencia otros frentes paramilitares, e incluso bandas criminales emergentes y bandas criminales al servicio del narcotráfico, con el objetivo de controlar las principales fuentes de financiamiento de esos grupos. (Fiscalía General de la Nación, 2011).

Finalmente, un informe de la Federación Nacional de Personeros de abril de 2013 indicó que la tendencia observada durante el último año ubicaba a los grupos armados ilegales surgidos después de la desmovilización de las AUC en los primeros lugares de la lista de actores responsables de hechos victimizantes contra la población civil, mientras que en años anteriores los actores principales eran los paramilitares y las guerrillas. Así, en tres de cada diez denuncias recibidas en las personerías, las víctimas 
identifican a miembros de estos grupos como sus victimarios (Comisión Interamericana de Derechos Humanos, 2013b).

La CIDH advierte que la desmovilización parcial de las autodefensas sumada a la actuación de grupos armados ilegales surgidos después de la desmovilización, han complejizado aún más las dinámicas del conflicto armado interno (Comisión Interamericana de Derechos Humanos, 2013b).

Respecto a lo anterior, el organismo manifestó que el Estado mantiene deberes específicos de desarticulación de las autodefensas que no participaron de las desmovilizaciones colectivas llevadas a cabo entre los años 2003 y 2006 y que continúan actuando en territorio colombiano. Adicionalmente, observó con preocupación que se verifican elementos de continuidad entre las antiguas autodefensas y las denominadas "bandas criminales emergentes". Al respecto, con base en la información disponible y la valoración producto de sus diferentes mecanismos de seguimiento:

[...] la CIDH ha identificado como elementos de continuidad: i) El tipo de actor, ii) Los destinatarios de las acciones de estos grupos, iii) El espacio geográfico en el que operan, iv) $\mathrm{Su}$ estructura interna, v) La cronología que puede establecerse entre la actuación de esos grupos, vi) El hecho de que la negación por parte del Estado de la continuidad de elementos del paramilitarismo hace más compleja y menos decisiva la respuesta, y vii) Hasta el momento, la ausencia de una investigación completa, sistemática $y$ diligente en relación con los miembros de las autodefensas. Estos elementos de continuidad plantean interrogantes sobre en qué medida los miembros de los grupos paramilitares efectivamente se desmovilizaron antes de plegarse o de crear otros grupos armados ilegales. (Comisión Interamericana de Derechos Humanos (2), 2013, s.p.)

La $\mathrm{CIDH}$ ha sido enfática al reiterar sobre la preocupante situación de impunidad que se verifica en relación con la comisión de graves violaciones a los derechos humanos e infracciones al DIH por parte de todos los actores del conflicto en Colombia, así como la falta de esclarecimiento de las dinámicas, alcances, composición y estructura de las antiguas autodefensas y los grupos armados ilegales surgidos después de la desmovilización de organizaciones paramilitares, constituyen obstáculos sistemáticos no solo para garantizar los derechos de las víctimas, sino también para contar con información detallada y precisa que permita caracterizar a estos grupos, desarticular los lazos que los nutren y adoptar las medidas políticas y jurídicas pertinentes para enfrentarlos (Comisión Interamericana de Derechos Humanos, 2013b).

Adicionalmente, varios organismos de la ONU se han expresado así:

- El Comité de Derechos Humanos señaló que disponía de "información que revelaba que el accionar de nuevos grupos emergentes después de la desmovilización en distintas partes del país concordaba con el modus operandi de los grupos paramilitares" (Comité de Derechos Humanos, 2010, s.p.).

- El Comité contra la Eliminación de la Discriminación Racial consideró que, si bien los grupos armados ilegales tenían una importante responsabilidad en las violaciones de derechos humanos, se seguía denunciando la participación o la colusión directa de agentes del Estado en esos actos. (Comité para la Eliminación de la Discriminación Racial, 2009)

- El Comité contra la Tortura indicó que, si bien los grupos armados ilegales tenían una importante responsabilidad en los casos de tortura, se seguía denunciando la participación o aquiescencia de agentes del Estado en esos actos. (Comité Internacional contra la Tortura, 2009);

- El Comité de Derechos Económicos, Sociales y Culturales los calificó como nuevos grupos paramilitares (Comité de Derechos Económicos, Sociales y Culturales, 2010);

- La Alta Comisionada para los Derechos Humanos de Naciones Unidas consideró que existían grupos fuertemente armados, que tenían organización militar y mandos responsables y disponían de capacidad para ejercer control territorial y adelantar acciones militares contra otros actores armados. (Oficina del Alto Comi- 
sionado para la Paz, 2009; Consejo de Derechos Humanos, 2012);

- En el año 2012, la Alta Comisionada indicó que el número de masacres y de víctimas atribuidas a los grupos armados ilegales surgidos después de la desmovilización de organizaciones paramilitares continuó aumentando, principalmente en Antioquia y Córdoba. Asimismo, señaló que la violencia ocurre en el contexto de enfrentamientos con otros grupos, o dentro del mismo grupo, en ocasiones contra grupos guerrilleros, y en varios casos se trata de ataques directos contra la población civil, y señaló que a la fecha de cierre del informe, el 53\% de los mandos de estos grupos capturados o muertos eran paramilitares desmovilizados (Consejo de Derechos Humanos, 2012).

\section{CONCLUSIONES}

En conclusión, algunas de las denominadas BACRIM pueden ser consideradas como una forma de neo paramilitarismo o paramilitarismo de última generación, teniendo en cuenta los datos recogidos por los organismos nacionales e internacionales en referencia a su accionar, modus operandi, permanencia en los controles territoriales, cooptación del estamento regional, utilización de armas pesadas, capacidad de reclutamiento y capacidad de daño. Lo que calificaría a ciertas bandas criminales como reconfiguraciones o continuidades del paramilitarismo de las AUC y sus estructuras regionales que para la época de la desmovilización dominaban ciertas zonas del país bajo la aplicación de controles sociales, combates con otros actores armados como guerrillas y fuerza pública, así como alianzas locales con instituciones públicas que permitían la permanencia y operación de estas estructuras armadas. En este sentido, se destaca la continuidad de la violación masiva y sistemática de derechos humanos, bajo las modalidades de desplazamientos forzados, asesinatos selectivos de líderes comunitarios, reclamantes de tierras, defensores de derechos humanos entre otros actores sociales que ponen en cuestión el dominio y la presencia territorial.

Así mismo, la continuidad con el narcotráfico y la minería como forma de financiación, siendo estos elementos de continuidad en las BACRIM, ya que, como se señaló en varias sentencias de justicia y $\mathrm{paz}^{2}$, han sido el motor financiero de estas estructuras armadas dentro del conflicto armado. Su incursión no se remonta a la desmovilización promovida en el marco de justicia y paz, sino que por el contrario es una variable que se ha gestado desde inicios de los años ochenta dentro de estas estructuras, con el MAS.

El Estado mantiene el derecho a reafirmar la soberanía y la integridad del territorio nacional, a combatir militarmente al enemigo irregular por los medios y métodos de guerra autorizados, a generar las condiciones de su debilitamiento, neutralización y derrota, o a optar, alternativamente, por un proceso de negociación tendiente a ponerle fin de forma pacífica al conflicto (Protocolo II, 1977). Por esta razón, la concesión de las amnistías más amplias posibles a la cesación de hostilidades del artículo 6 párrafo 5 del Protocolo II es una cláusula declarativa que promueve la reconciliación entre las partes en conflicto y el restablecimiento de las relaciones en una nación dividida; sin embargo, no supone una imposición internacional sobre un asunto que cae exclusivamente dentro de las competencias de los órganos políticos y el proceso democrático del Estado en cuestión. del Tribunal Superior de Distrito Judicial de Bogotá Sala de Justicia y Paz, del año 2013 con número de radicado: 110016000253200680012 , de Ramiro Vanoy Murillo alias "Cuco Vanoy", del Tribunal Superior de Distrito Judicial de Medellín Sala de Justicia y Paz, del año 2015 con número de radicado: 110016000253200680018. 


\section{BIBLIOGRAFÍA}

- Alta Comisionada de las Naciones Unidas para los Derechos Humanos. (2010). Informe anual sobre la situación de los derechos humanos en Colombia A/HRC/13/72. 4 de marzo de 2010.

- Alta Comisionada de las Naciones Unidas para los Derechos Humanos. (2011). Informe sobre la situación de los derechos humanos en Colombia, Doc. A/HRC/16/22. 3 de febrero de 2011.

- Caso La Tablada, 11.137. (1997).Comisión Interamericana de Derechos Humanos.

- Caso Limaj, IT-03-66. (2007). Tribunal Penal Internacional para la Ex Yugoslavia.

- Caso Abu Garda, ICC-02/05-02/09.( 2010). Corte Penal Internacional.

- Caso Dordevic, IT-05-87/1-T. (2011). Tribunal Penal Internacional para la Ex Yugoslavia.

- Centro de Memoria Histórica. (2015). Rearmados y reintegrados panorama de las AUC.

- Centro Nacional de Memoria Histórica. (2012). Justicia y Paz ¿Verdad judicial o verdad

- histórica? Bogotá: Taurus.

- Centro Nacional de Memoria Histórica. (2012b). Justicia y Paz, Tierras y Territorios en las Versiones de lso Paramilitares. Bogotá: CMH.

- Centro Nacional de Memoria Histórica.(2014c). Nuevos Escenarios de Conflicto Armado

- y Violencia - Región Caribe, Departamento de Antioquia y Departamento de Chocó,

- Panorama posacuerdos con AUC. Bogotá: Imprenta Procesos Digitales.

- Centro Nacional de Memoria Histórica. (2012). Justicia y Paz ¿Verdad judicial o verdad histórica? Bogotá: Taurus.

- Centro Nacional de Memoria Histórica. (2014). Nuevos Escenarios de Conflicto Armado y Violencia - Región Caribe, Departamento de Antioquia y Departamento de Chocó,

- Panorama posacuerdos con AUC. Bogotá: Imprenta Procesos Digitales.

- CIDH. (2013). Informe del país de Colombia. Verdad, justicia y reparación. OEA/Ser.L/V/II. Doc. 49/13.

- Comisión Colombiana de Juristas. (2013). Algunas anotaciones sobre Bacrim y paramilitares. Recuperado de: http:// w w w.coljuristas.org/d ocumentos / pronunciamientos/algunas_anotaciones_sobre_ bacrim_y_paramilitares.pdf

- Comisión Interamericana de Derechos Humanos. (2013b). Verdad, Justiciay Reparación. Washington.

- Comisión Interamericana de Derechos Humanos. (2009). Informe Anual de la Comisión Interamericana de Derechos Humanos 2009, OEA/Ser.L/V/II., Doc. 51 corr. 1. Washington.

- Comisión Nacional de Reparación y Reconciliación. (2010). La Reintegración. Logros en medio de rearmes y dificultades no resueltas. Bogotá.

- Corte Constitucional. (2007). Sentencia C-291. Dr. Manuel José Cepeda Espinosa

- Corte Constitucional. (2012). Sentencia C-781. Dra. María Victoria Calle Correa

- Defensoría del Pueblo. (2008). Informe de Riesgo No 026-08 A.I. San Jose de Apartado. SAT.

- Defensoría del Pueblo. (2009). Informe de Riesgo N 022-09.

- ---. (2011a). Informe de Riesgo N 014-11 A.I.

- ---- (2011b). Nota de seguimiento $\mathrm{N}^{\circ} 011-11$.

- ---. (2012a). Nota de seguimiento $\mathrm{N}^{\circ}$ 006-12.

- ----. (2012b). Defensor del Pueblo rechaza paro armado en Urabá.

- ----. (2012c). Vigésimo Informe del Defensor del Pueblo al Congreso de la República.

- ---. (2013a). Informe de riesgo No.013-13.

- ----. (2013b). Defensoría del Pueblo advierte sobre nuevos desplazamientos masivos en Chocó.

- ----. (2013c). Nota de seguimiento 005. Bogotá.

- ----. (2014a). Crisis Humanitaria en Chocó. Diagnóstico, valoración y acciones de la Defensoría del Pueblo.

- ----. (2014b). Defensoría advierte presencia de "bandas criminales" en 168 municipios de 27 departamentos.

- ---. (2014c). Informe de riesgo 30-14.

- Fiscal especializada para la Operación Agamenón 2015, citada en Verdad Abierta. (2015). Los secretos del 'Clan Úsuga'. Recuperado de http://www.verdadabierta. com/rearme/5933-los-secretos-del-clan-usuga,

- Fiscalía General de la Nación . (2012). CTI se incauta de armas de "Los 
Urabeños". Recuperado de: https:// www.fiscalia.gov.co/colombia/noticias / cti-se-incauta-de-armas-de-los-urabenos/

- ---.(2013a). Capturada ciudadana alemana por vínculos con Los Urabeños. Recuperado de: https://www.fiscalia.gov.co/colombia/noticias/ capturada-ciudadana-alemana-por-vinculos-conlos-urabenos/

- ----. (2013b). Tribunal Superior de Justicia y Paz de Bogotá excluyó a Daniel Rendón Herrera, alias Don Mario. Recuperado de: https://www. fiscalia.gov.co/colombia/noticias/tribunalsuperior-de-justicia-y-paz-de-bogota-excluyo-adaniel-rendon-herrera-alias-don-mario/

- ---. (2013c). Apreciación 2do trimestre 2013. Derecho Humanos y Derecho Internacional Humanitario.

- ----. (2013d). Capturado presunto integrante de Los Urabeños con un arsenal. Recuperado de: https://www.fiscalia.gov.co/colombia/noticias/ capturado-presunto-integrante-de-los-urabenoscon-un-arsenal/

- ----. (2013e). Cincuenta bandoleros condenados en Antioquia en dos años. Recuperado de: https: //www.fiscalia.gov.co/colombia/ noticias/cincuenta-bandoleros-condenados-enantioquia-en-dos-anos /

- ----. (2013f). Condenados por desplazamiento forzado urbano de personas en Medellín. Recuperado de: https://www.fiscalia.gov. co/colombia/noticias/condenados-pordesplazamiento-forzado-urbano-de-personasen-medellin/

- ---. (2014). Amenazas de grupos armados obligan a 13 concejales de El Tambo (Cauca) a salir del municipio. Recuperado de: http://www. defensoria.gov.co/es/nube/regiones/1027/ Amenazas-de-grupos-armados-obligan-a13-concejales-de-El-Tambo-(Cauca)-a-salirdel-municipio-conflicto-armado-cauca-ElTambo-desplazamiento-Conflicto-armadoDesplazados-Derechos-Humanos.htm

- ----. (2015). Condenado miembro de Los Urabeños a 33 años de cárcel por ataque a local comercial. Recuperado de: https://www.fiscalia.gov.co/ colombia/noticias/condenado-miembro-de-losurabenos-a-33-anos-de-carcel-por-ataque-alocal-comercial/

- ----. (2011). Fiscalía General de la Nación, Informe de Gestión, agosto de 2009- noviembre de 2010. Bogotá.

- Fundación Ideas para la Paz. (2013). Narcotráfico: Génesis de los paramilitares y herencia de bandas criminales. Serie Informes No. 19. Bogotá: Fundación Ideas para la Paz.

- Fundación Ideas para la Paz. (2014). Dinámicas del conflicto armado en el nudo del paramilitarismo.

- Fundación Seguridad y Democracia. (2007). El nuevo escenario paramilitar. Recuperado de:

- http://sedici.unlp.edu.ar/bitstream / handle/10915/37259/Documento_completo_. pdf?sequence $=3$ \&isAllowed $=y$

- Human Right Watch. (2001). Más allá de la negociación: El derecho internacional humanitario y su aplicación la conducta de las FARC-EP. Washington D.C: HRW.

- Human Rights Watch. (1996). La historia de la asociación militar-paramilitar.

- Human Rights Watch. (2010). Herederos de los paramilitares. La nueva cara de la violencia en Colombia.

- Policía Nacional de Colombia. (2015). Intervención de la Policía Nacional en Urabá contra "El Clan Úsuga".

- ---. (2009). Gobierno y policía actualizan afiche de recompensas por cabecillas de narcotráfico y bandas criminales. Recuperado de: http://oasportal.policia.gov.co/portal/pls/ portal/JOHN.NOTDET_DIRECCION_GENERAL. SHOW?p_arg_names=identificador \&p_arg_ values $=229742$.

- Restrepo, J., González, J. D., y Tobón, A. (2011). Paramilitarismo: la amenaza sigue viva.

- Vité, S. (2009). Criminalitè organisèe peut-on parle de conflict armé au sens où l'entend le droit internacional humanitaire. En C. o. CICR, Armed Conflicts and Parties to Armed Conflicts under IHL: Confronting Legal Categories to Contemporary Realities (págs. 69-77). Bruselas. 